\title{
Controle de oídio em pepino parternocárpico com produtos alternativos em cultivo protegido*
}

\author{
Gilmara de Sá Faria ${ }^{1}$; João Batista Vida ${ }^{1,3}$; Jaqueline Rosemeire Verzignassi ${ }^{1,2}$; Dauri José Tessmann ${ }^{1,3}$; Emi \\ Rainildes Lorenzetti ${ }^{1}$, Francielli Gasparotto ${ }^{1,2}$
}

${ }^{1}$ Universidade Estadual de Maringá, Dep. de Agronomia, Av. Colombo, 5790, 87020-900, Maringá-PR; ${ }^{2}$ Bolsista CAPES; ${ }^{3}$ Bolsista de produtividade, CNPq; *Trabalho financiado pela Fundação Araucária.

Autor para correspondência: João Batista Vida (jbvida@uem.br)

Data de chegada: 10/12/2008. Aceito para publicação em: 10/10/2011.

\section{RESUMO}

1640

Faria G. S.; Vida, J.B.; Verzignassi J.R.; Tessmann, D.J.; Lorenzetti, E.R.; Gasparotto, F. Controle de oídio em pepino parternocárpico com produtos alternativos em cultivo protegido. Summa Phytopathologica, v.37, n.4, p.205-207, 2011.

O oídio é a doença mais importante para pepino partenocárpico em cultivo protegido na Região Norte do Paraná, em períodos de baixa umidade. As características desse agrossistema propiciam condições favoráveis ao uso de medidas alternativas para o controle dessa doença. Assim, cinco produtos alternativos foram avaliados para o controle de oídio em pepino partenocárpico, híbrido Hokushin, em cultivo protegido: leite cru de vaca, óleo de nim, acibenzolar-s-metil, extrato aquoso de cama de frango, extrato cítrico (Ecolife ${ }^{\circledR} 40$ ) e o fungicida azoxistrobin, nas concentrações (ingrediente ativo por litro de água): $50,0 \mathrm{ml} ; 5,0 \mathrm{ml} ; 0,025 \mathrm{~g} ; 2,0$ $\mathrm{ml}$ da diluição $1: 2 \mathrm{v} / \mathrm{v}$, e $0,06 \mathrm{~g}$, respectivamente. Os melhores resultados foram verificados para o óleo de nim, com eficiência de controle superior a azoxistrobin $(36,8$ e $27,8 \%$, respectivamente). Extrato de cama de frango e ecolife apresentaram os piores desempenhos, com eficiência de controle de 6,5 e $10,5 \%$, respectivamente.

Palavras-chave adicionais: Oidium spp., Cucumis sativus, controle alternativo, míldio pulverulento

\section{ABSTRACT}

Pinto, Z.V.; Cipriano, M.A.P.; Galvão, J.A.H.; Bettiol, W.; Patrício, F.R.A.; Santos, A.S. Downy mildew control by alternatives produts in cucumber under protect cultivation. Summa Phytopathologica, v.37, n.4, p.205-207, 2011.

Powdery downy is the most important disease in parthenocarpic cucumbers kept under protected cultivation in the northern region of Paraná State-Brazil during low-humidity periods. The characteristics of this agrosystem proved favorable conditions for the adoption of alternative measures to control this disease. Thus, five alternative products were evaluated for powdery mildew control in the parthenocarpic cucumber 'Hokushin' under protect cultivation: raw cow's milk, neem oil, acibenzolar-S-methyl, poultry litter water extract, citric extract $\left(\right.$ Ecolife $\left.^{\circledR} 40\right)$ and the fungicide azoxystrobin, at the following concentrations (active ingredient per liter of water): $50.0 \mathrm{ml} ; 5.0 \mathrm{ml} ; 0.025 \mathrm{~g} ; 2.0 \mathrm{ml}$, $1: 2 \mathrm{v} / \mathrm{v}$. dilution, and $0.06 \mathrm{~g}$, respectively. Neem oil led to the best results with control efficiency higher than of azoxystrobin $(36.8$ and $27.8 \%$, respectively). Poultry litter extract and Ecolife had the worst performance, with 6.5 and $10.5 \%$ control efficiency, respectively.

Keywords: Oidium sp., Cucumis sativus, powdery mildew

Nas estações de secas e de temperaturas mais baixas na Região Norte do Paraná, o oídio se constitui na mais importante doença em pepino partenocárpico ("pepino japonês") em cultivo protegido $(1,8)$. Nesta Região, as espécies telemorfas de Oidium mais importantes para a cultura do pepino são Podosphaera xanthii e Golovinomyces cichoracearum [sinonímias Sphaerotheca fuliginea (Schlecht) Pollacci e Erysiphe cichoracearum Jacz.] (5).

Nos últimos anos, em diferentes espécies agronômicas têm sido obtidos resultados positivos do uso de produtos alternativos para o controle de oídio, principalmente sob condições controladas: leite de vaca crú diluído até $50 \%$ (2), extratos aquosos originados de diferentes compostos orgânicos (4) e óleo de nim indiano (5). Mas, a implementação dessas medidas em agrossistemas produtivos tem sido pouco explorado. Porém, as características do cultivo protegido
$(7,8)$ e a colonização ectoparasítica de Oidium sp. potencializam o emprego de produtos alternativos com eficiência técnica e viabilidade econômica. Assim, esse trabalho teve como objetivo avaliar a eficiência dos produtos alternativos leite de vaca crú, óleo de nim, extrato cítrico, extrato de cama de frango e acinbenzolar-smetil no controle de oídio em pepino partenocárpico no agrossistema cultivo protegido.

O ensaio experimental foi realizado na Região Norte Estado do Paraná, durante as estações primavera-verão, numa estufa plástica tipo túnel alto. As mudas do híbrido de pepino partenocárpico Hokushin, considerado de alta suscetibilidade a Oidium spp., foram produzidas em células de bandeja de isopor, contendo substrato comercial. Para a condução da cultura, adotaram-se as técnicas recomendadas por Cañizares (1997). Passados 19 dias da emergência, 
as mudas foram transplantadas para sulcos em canteiros, obedecendo ao espaçamento de $1,0 \mathrm{~m}$ entre linhas e $0,30 \mathrm{~m}$ entre plantas. No plantio procederam-se as adubações orgânica com húmus e química $(\mathrm{N}, \mathrm{P}, \mathrm{K}, \mathrm{Zn}$ e $\mathrm{B})$ e, em cobertura ( $\mathrm{N}$ e $\mathrm{K})$. A irrigação foi por gotejamento de acordo com a necessidade da cultura, assim como o molhamento nas entrelinhas. Os produtos testados para o controle de oídio foram: leite de vaca crú diluído na dosagem de $50 \mathrm{ml} / \mathrm{l}$ de água, extrato aquoso de cama de frango diluído 1:2 v/v, extrato cítrico (Ecolife ${ }^{\circledR} 40$ ), acibenzolar-s-metil (Bion ${ }^{\circledR}$ ) e óleo de nim, nas dosagens do ingrediente ativo (i.a.) de 2,0 $\mathrm{ml} ; 0,025 \mathrm{~g} \mathrm{e} 5,0 \mathrm{ml}$, respectivamente, para cada litro de água. Como fungicida padrão utilizou-se azoxistrobin na dosagem de 0,06 $\mathrm{ml}$ i.a./litro de água. Para acibenzolar-s-metil, as pulverizações foram iniciadas aos 10 dias após o transplante das mudas, antes do aparecimento dos primeiros sinais de Oidium spp.. Quando surgiram as primeiras colônia de oídio nas folhas (20 dias após o transplante), iniciaram-se as pulverizações com os demais produtos. O intervalo entre as pulverizações foi semanal, sendo de 10 dias para Ecolife 40 , para evitar possíveis problemas de fitotoxicidade. Para as pulverizações, utilizou-se pulverizador costal pressurizado por $\mathrm{CO}_{2}$, com aplicação de volume da calda fungicida procurando obter $\mathrm{o}$ máximo de cobertura foliar. A avaliação de oídio foi realizada semanalmente, quantificando-se a severidade da doença: para cada folha adulta, em cada planta foi avaliado o percentual de superfície com sintomatologia da doença. Na planta, a severidade de oídio foi calculada pela média aritmética simples do somatório da severidade da doença em cada folha. Também se utilizou a área abaixo da curva de progresso da doença (AACPD) para a análise da evolução da doença em cada tratamento. Diariamente, os frutos que apresentaram comprimento entre 20 e $22 \mathrm{~cm}$ foram colhidos e contados. O delineamento experimental empregado foi de blocos ao acaso, com quatro repetições para cada tratamento, com a parcela útil representada por cinco plantas.

Os resultados indicaram que as primeiras colônias de oídio foram observadas aos 27 dias após o transplantio das mudas (DAT), ocorrendo infecção um pouco tardia na cultura. Até o $40 \mathrm{DAT}$, o desenvolvimento da doença foi lento, com no máximo 15,2 \% de severidade no tratamento testemunha. A explosão epidemiológica de oídio ocorreu somente após 40 DAT. As curvas de desenvolvimento de oídio ao longo do tempo mostraram que houveram grandes diferenças entre a eficiência dos produtos testados quanto ao progresso da doença (Figura 1). Até 48 DAT, o melhor controle ocorreu para o azoxistrobin e o óleo de nim, com valores aproximados 5,0 e 11,0\% de severidade, respectivamente. Também acibenzolar-s-metil apresentou bom controle. Para extrato aquoso de cama de frango, a severidade foi de $40,0 \%$, sendo o pior produto, mas mesmo assim apresentou algum nível de controle em relação à testemunha. Aos $55 \mathrm{DAT}$, estádio em que a cultura atingiu o pico de produção, para o óleo de min, a severidade de oídio foi relativamente baixa $(28,5 \%)$; com melhor desempenho do que azoxistrobim $(32,0 \%)$. Para os demais produtos, a severidade foi superior a $50,0 \%$, chegando a $73,5 \%$ no tratamento testemunha. Mesmo aos 69 DAT, a eficiência de controle do óleo de mim ainda foi elevada (severidade de 48,0 \%), superior a azoxistrobim (75,0 $\%)$. Também para esse período pós-transplantio, para todos os outros produtos houve elevada severidade de oídio, variando entre 80,5 a $89,0 \%$ (Figura 1 ).

Para pepino partenocárpico, uma cultura de colheita precoce e múltipla, de crescimento e ciclo rápidos, o prolongamento de uma semana de proteção contra patógenos nos estádios iniciais da cultura pode resultar em significativa redução de danos. Severas epidemias, nesses estádios podem resultar em severos danos.

Para a AACPD (tabela 1) observou-se a mesma tendência dos resultados anteriores: o óleo de min apresentou melhor desempenho, se equiparando ao fungicida azoxistrobim. Também com resultado significativa foi o desempenho do acibenzolar-s-metil. Os demais produtos não diferiram do tratamento testemunha, quanto à severidade de oídio.

Quanto à porcentagem de controle de oídio, o óleo de min e acibenzolar-s-metil proporcionaram 36,8 e 27,8 \% de eficiência, respectivamente, em relação à testemunha. $\mathrm{O}$ extrato de cama de frango apresentou o pior desempenho, com $6,5 \%$ de eficiência de controle.

Aspectos contrastantes ocorreram para produção (número de frutos), em relação aos resultados relacionados ao controle oídio para
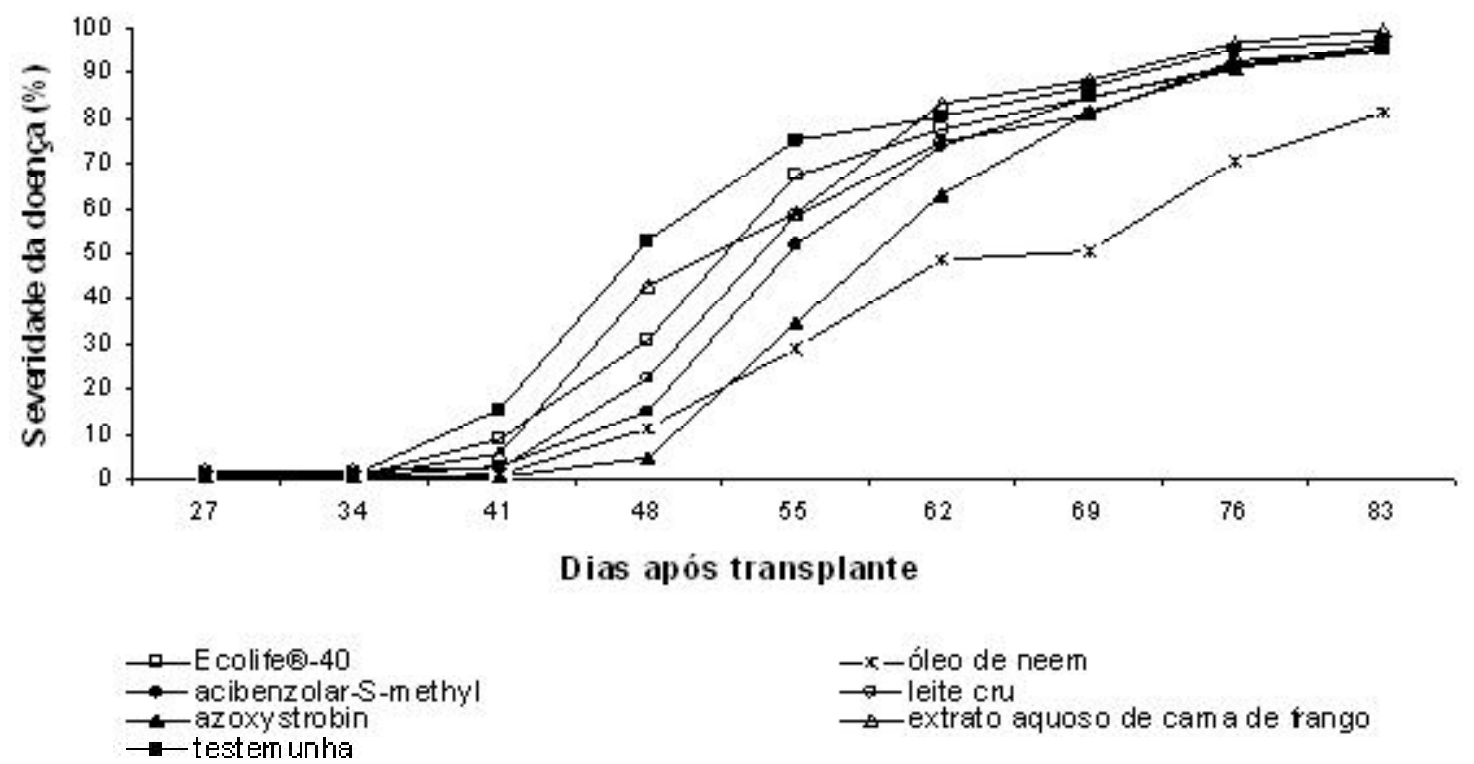

Figura 1. Controle de oídio em pepino, híbrido Hokushin, por produtos alternativos em cultivo protegido. 
Tabela 1. Eficiência de produtos alternativos no controle de oídio em pepino partenocárpico, híbrido Hokushin, em cultivo protegido. Maringá-PR, 2008.

\begin{tabular}{|c|c|c|c|}
\hline Tratamento & $\mathrm{AACPD}^{1}$ & $\%$ de controlefinal & $\mathrm{N}^{0}$ de frutos comerciais \\
\hline Testemunha & $3191,29^{2}$ a & 0,00 & $73,1^{2}$ a \\
\hline Extrato de cama de frango & $2982,96 \mathrm{ab}$ & 6,53 & $150,4 \mathrm{c}$ \\
\hline Extrato cítrico & $2859,43 \mathrm{ab}$ & 10,49 & 104,9 b \\
\hline Leite cru de vaca & $2665,98 \mathrm{abc}$ & 16,47 & $112,6 \quad b$ \\
\hline Acibenzolar-s-metil & $2571,59 \mathrm{bcd}$ & 19,42 & $101,6 \mathrm{~b}$ \\
\hline Azoxistrobin & $2265,21 \mathrm{cde}$ & 27,85 & $127,3 \mathrm{bc}$ \\
\hline Óleo de nim & $2014,22 \mathrm{e}$ & 36,89 & $122,5 \mathrm{bc}$ \\
\hline
\end{tabular}

CV $(\%) \quad 9,04 \quad 29,4$

${ }^{1}$ AACPD: área abaixo da curva de progresso de doença; ${ }^{2}$ os dados representam média de quatro repetições e quando seguidos da mesma letra não diferem entre si na vertical (Tukey a $5 \%$ ).

alguns tratamentos. Para extrato de cama de frango houve elevada severidade da doença, não diferindo da testemunha. No entanto foi o tratamento que apresentou maior produção (Tabela 1). Provavelmente este fato se deveu às propriedades nutricionais da cama de frango, associadas ao surgimento um pouco tardio de oídio na cultura. Neste tratamento observou-se, visualmente o maior vigor das plantas. A cama de frango possui elevadas concentrações de vários micro e macronutrientes (6), que podem ser absorvidos via foliar.

O elevado nível de controle proporcionado pelo óleo de nim observado neste trabalho, se igualando ao fungicida azoxistrobin, o condiciona como um produto alternativo para o controle de oídio em cultivo protegido.

\section{REFERÊNCIAS BIBLIOGRÁFICAS}

1. Aguiar, B. M. Caracterização morfológica e molecular de Oidium spp. em cucurbitáceas. 2005. 60f. Dissertação (Mestrado em Agronomia) - Departamento de Agronomia, Universidade Estadual de Maringá, Maringá.

2. Bettiol, W. Effectiveness of cow's milk against zucchini squash powdery mildew (Sphaerotheca fuliginea) in greenhouse con- ditions. Crop Protection, v.18, p. 489-492, 1999

3. Cañizares, K. A. L. A cultura do pepino. In: Gotto, R.; Tivelli, S.W. (eds.) Produção de hortaliças em ambiente protegido: condições subtropicais. Botucatu: Unesp. 1997, p. 195223.

4. Ishida, A. K. N.; Bettiol, W.; Souza, R. M. Controle de oídio (Sphaerotheca fuliginea (Schlecht. et Fr.) Poll.) da abobrinha com extratos aquosos de matéria orgânica. Ciência Agrotécnica, v. 25 , p.1229-1234, 2001

5. Konstantinidou-Doltsinis, S.; Schmit, A. Impact of treatment with plant extracts from Reynoutria sachalinensis (F. Schmidt) Nakai on intensity of powdery mildew severity and yield in cucumber under high disease pressure. Crop Protection, v.17, p. 649-656, 1998.

6. Malavolta, E.; Pimentel-Gomes, F.: Alcarde, J.C. Adubos e adubações. São Paulo: Nobel, 2002. 200 p.

7. Tivelli, S. W. Manejo do ambiente em cultivo protegido. . In: Gotto, R.; Tivelli, S.W. (Ed.) Produção de hortaliças em ambiente protegido: condições subtropicais. Botucatu: Unesp. 1997, p.15-31. In: Gotto, R.; Tivelli, S.W. (Eds.). Botucatu: Unesp. 1997, p. 195-223.

8. Vida, J. B.; D. J. Tessmann; Oliveira, R. R. Controle de doenças de hortaliças em cultivo protegido. In: Verzignassi, J. R.; Poltronieri, L. S. (Ed.) Pragas e doenças de cultivos amazônicos. Belém: Emprapa-Amazônia Oriental, 2007. p. 68-96. 